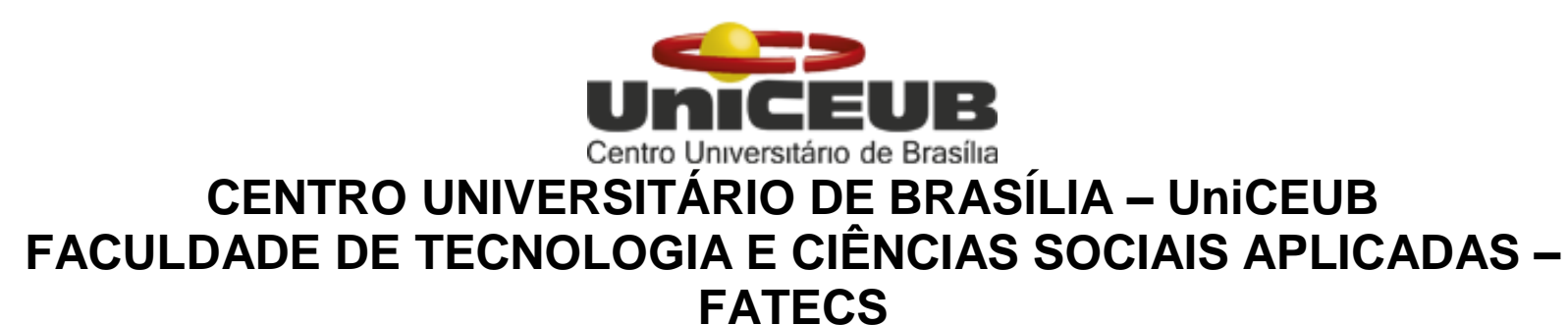

PROGRAMA DE INICIAÇÃO CIENTÍFICA

NOME DO(S) ALUNO(S)

PAULO GABRIEL FERREIRA DE GUSMÃO

CAROLINA ALMEIDA PEREIRA

GERAÇÃO DE ENERGIA SOLAR RESIDENCIAL EM FUNÇÃO DAS

VARIAÇÕES DA INTENSIDADE LUMINOSA APLICADAS EM UM

PAINEL FOTOVOLTAICO 


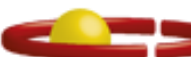 \\ vizcicun \\ Centro Unıversıtárıo de Brasílıa \\ NOME DOS ALUNOS \\ PAULO GABRIEL FERREIRA DE GUSMÃO CAROLINA ALMEIDA PEREIRA
}

\section{GERAÇÃO DE ENERGIA SOLAR RESIDENCIAL EM FUNÇÃO DAS VARIAÇÕES DA INTENSIDADE LUMINOSA APLICADAS EM UM PAINEL FOTOVOLTAICO}

\author{
Relatório final de pesquisa de Iniciação Científica \\ apresentado à Assessoria de Pós-Graduação e \\ Pesquisa pela Faculdade de Tecnologia e \\ Ciências Sociais Aplicadas - FATECS \\ Orientação: Nome do(a) professor(a) \\ Msc. Luciano Henrique Duque
}

\section{BRASÍLIA-DF \\ 2016}




\section{Resumo do Projeto}

Esse projeto propõe um sistema para otimização de geração de energia solar residencial em função da intensidade luminosa, com o objetivo de aumentar a capacidade de geração de eletricidade por um painel fotovoltaico. O sistema será composto por um microcontrolador Arduíno e vários componentes eletrônicos discretos, como sensores de luminosidade, corrente e motores. Os foto-sensores convertem a luz incidente aplicada ao painel solar e transmitem as informações ao Arduíno que, processa os dados e aciona uma base móvel, composta por um motor de passo acoplado ao painel solar. O azimute do conjunto é ajustado de forma a encontrar a posição em que ocorra a maior incidência de raios solares e dessa forma aumenta a geração de energia pelo painel. Os dados de energia coletados pela célula são transferidos para um dispositivo móvel e/ou computador via internet e analisado por um software específico. Os dados coletados são analisados e gráficos de gerações e consumo de energia da residência são informados e podem ser enviados para qualquer dispositivo móvel. A ideia é criar uma tecnologia de custo acessível a toda população, com vistas à geração de energia própria e possibilitando a redução do consumo da energia vinda das usinas térmicas e hidrelétricas, assim é possível contribuir para um país mais consciente e capaz de gerar formas alternativas de energia.

Palavras-chave - Microcontorlador. Arduino. Energia Solar 


\section{Sumário}

1. Introdução .5

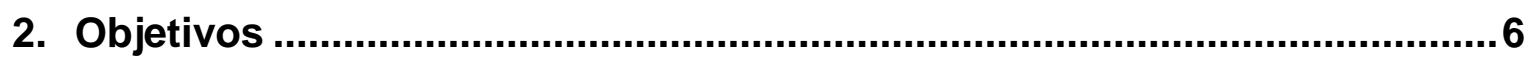

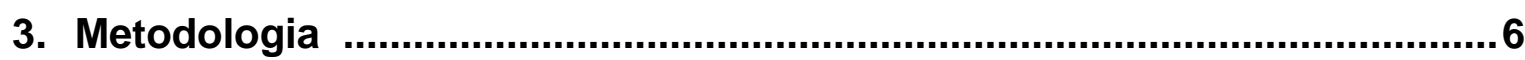

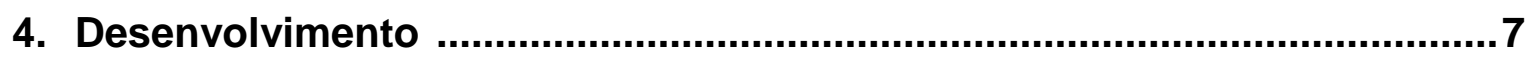




\section{Introdução}

A energia elétrica pode ser gerada através de diferentes fontes, no Brasil ela em sua grande maioria vem das usinas hidrelétricas, que utilizam as quedas d'água dos rios para gerar eletricidade, o Brasil já explora grande parte de suas enormes bacias hidrográficas para geração de energia hidroelétrica (ANEEL, 2010), sendo assim há necessidade de explorar meios alternativos para geração de energia. $A$ energia elétrica é muito importante em nossas residências, porém o mais importante é utilizá-la de forma racional, sempre consumindo o necessário e assim estaremos contribuindo para preservação de nosso meio ambiente. O aumento do desperdício de energia elétrica implica obrigatoriamente no aumento da potência instalada de geração (MARTINS, 1999).

O grande desafio do século XXI deverá ser suprir a humanidade e suas metrópoles e parques industriais com energia limpa, renovável e barata, principalmente o Brasil que vive uma eminência de crise energética em função da falta de chuvas. A cada ano aumenta a demanda por energia elétrica, o que causa cada vez mais pressão nos mananciais de hidrocarbonetos, cujos estoques deverão ser esgotados nos próximos 30, 40 anos (BRASIL, 1999).

Observa-se que em períodos de seca os reservatórios estão cada vez mais baixos e na eminência de um colapso, por consequência, as usinas termoelétricas estão sendo acionadas cada vez mais, e assim permanecem por longos períodos. $O$ custo das termoelétricas são maiores se comparado com as hidrelétricas.

Segundo Al Gore (2006), um dos maiores desafios do século XXI, é a preservação e recuperação do meio ambiente. Mais precisamente o impacto causado ao meio ambiente pelas atividades humanas. Sabe-se que é impossível deixar de impactar o meio ambiente, entretanto deve-se ter responsabilidade e tomar providências para que toda energia gerada seja usada da forma mais eficiente e racional possível. Portanto, será necessário dispor de fontes alternativas de energia que reduzem o impacto ambiental e ainda possa minimizar os problemas de falta de água nos reservatórios no Brasil.

Esse projeto visa melhorar a eficiência na geração de energia por uma célula fotovoltaica, obtendo uma maior potência gerada possível. O microcontrolador Arduíno atuará de forma a posicionar o painel solar diretamente para o Sol, 
aumentando a potência gerada em relação a um sistema com painel fixo. Um estudo matemático da posição do sol em relação a terra será realizado e programado via software no Arduíno. A otimização na geração contribui para uma maior eficiência e torna o sistema de energia solar dinâmico em sua geração. Nesse cenário, o projeto proposto tem por objetivo agregar valores na área de geração de energia solar residencial, agindo em prol de um desenvolvimento sustentável, utilizando sempre o necessário, sem comprometer as gerações atuais e futuras.

\section{Objetivos}

O objetivo geral é maximizar a geração de energia elétrica solar residencial por um painel fotovoltaico, capaz de posicionar o painel, no eixo azimute, de forma a captar a maior intensidade de raios solares, aumentado à eficiência do sistema e tornar os custos cada vez mais acessíveis à população em geral.

Os objetivos específicos são aqueles necessários e pontuais para atingir o alvo principal. Nesse cenário, os objetivos específicos pautam- se em:

- Realizar uma revisão bibliográfica sobre o funcionamento da célula fotovoltaica, o posicionamento do sol em relação à superfície da terra, o microcontrolador Arduíno e os sensores de luminosidade (LDR);

- Projetar um sistema capaz de realizar o controle do posicionamento do painel, no eixo azimute, conforme a variação solar incidente em sua superfície;

- Armazenar e processar as informações de tensão e corrente para serem utilizados como tomada de decisão no movimento do painel fotovoltaico;

- Elaborar um hardware baseado na arquitetura Arduíno com suas interfaces e periféricos para controle do painel fotovoltaico;

- Efetuar testes de desempenho no protótipo e realizar ajustes conforme a necessidade.

\section{Metodologia}

Inicialmente como metodologia é feita uma pesquisa sobre os componentes eletrônicos necessários e suas funções, tais como: sensores de luminosidade (LDR), microcontrolador Arduíno, motores de passo, transistores, inversores de frequência, baterias e painéis fotovoltaicos. Após um estudo sobre os elementos evolvidos no 
sistema de rastreamento solar, inicia-se então a montagem dos equipamentos integrantes para o funcionamento de um sistema de geração de energia solar offgrid, e a confecção do circuito para controle do motor responsável pelo posicionamento do painel. Dividindo-se nos seguintes módulos:

- $\quad$ Módulo da Célula Fotovoltaica: responsável pela conversão de energia luminosa em energia elétrica para uso em uma residência;

- $\quad$ Módulo de Controle: responsável por controlar a distribuição da energia gerada pelo painel fotovoltaico entre o que será armazenado e o que será consumido.

- Módulo de Armazenamento: responsável por armazenar a energia gerada pelo painel fotovoltaico.

- Módulo de Conversão: responsável por converter os valores de tensão e corrente contínua gerados pelo painel solar, em valores de tensão e corrente alternada para alimentar o quadro geral e assim alimentar lâmpadas e tomadas do painel.

- Módulo Digital: responsável por receber os dados gerados pelos sensores de variação luminosa, convertendo em sinais digitais e acionando o motor para o posicionamento do painel fotovoltaico.

- Módulo do Motor: responsável por receber comandos do módulo digital, passando por uma ponte $\mathrm{H}$ e energizando as bobinas para posicionar o painel solar;

Para complementar a metodologia, os testes nos módulos citados acima vão utilizar: Multímetro digital, Simulador de circuito eletrônico Proteus (PROTEUS, 2010), e teste prático de funcionalidade.

\section{Desenvolvimento}

Para o desenvolvimento do projeto, é necessário entender as células fotovoltaicas, sistemas de controle e inversão de energia, armazenamento de energia elétrica, resistores dependentes de luz (LDR), sistema de geração solar offgrid e conhecer bem as funcionalidades dos microcontroladores da família Arduíno. 


\subsection{Módulo da Célula Fotovoltaica}

Células fotoelétricas ou fotovoltaicas são dispositivos capazes de transformar a luminosidade recebida, proveniente de fontes de luz, em energia elétrica. Uma célula fotoelétrica pode funcionar como geradora de energia elétrica através dos efeitos da radiação (luz e calor) sobre determinados materiais, particularmente os semicondutores, como o silício e o germânio (ANEEL, 2016).

Nesse projeto utiliza-se um painel fotovoltaico da canadian solar com capacidade de geração máxima de 245 Watts de potência (Figura 1). O painel fotovoltaico utilizado no projeto possui selo PROCEL letra $A$ em eficiência energética, ou seja, possui a maior eficiência na conversão de energia solar para energia elétrica presente no mercado brasileiro.

O PROCEL (Programa Nacional de Conservação de Energia Elétrica) é um programa governamental, coordenado pelo Ministério de Minas e Energia e executado pela Eletrobrás (PROCEL, 2016). O programa é responsável, dentre outras responsabilidades, por qualificar através do selo PROCEL os equipamentos eletroeletrônicos ao que tange a respeito de sua eficiência energética. No caso dos painéis fotovoltaicos, o selo PROCEL qualifica estes equipamentos em categorias que variam de $\mathrm{A}$ para os mais eficientes à $\mathrm{E}$ para os menos eficientes.

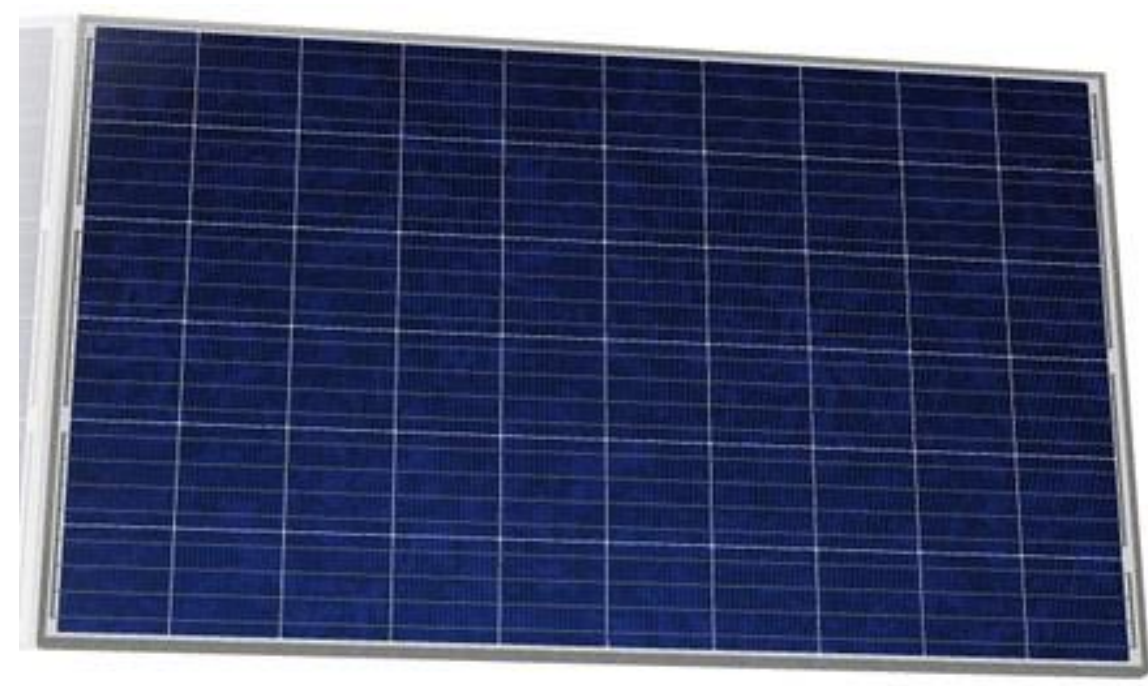

Figura 1 - Painel Fotovoltaico 245 W. 


\subsection{Módulo de Controle}

No projeto utiliza-se, para controle da energia elétrica gerada, um controlador de carga PWM (Pulse Width Modulation), devido seu custo inferior em relação ao controlador MPPT (Maximum Power Point Tracking) sendo que o mesmo atende as necessidades do projeto (NeoSolar, 2016).

O controlador de carga é um dos principais componentes de um sistema solar fotovoltaico off-grid, sendo ele o responsável pela duração do banco de baterias que por sua vez é um dos sistemas mais dispendiosos presente nos sistemas solares off-grid. A função do controlador de carga, é a de proteger o sistema de baterias de serem sobrecarregadas, ou descarregadas profundamente, e assim garantir que toda a energia gerada pelos painéis fotovoltaicos seja armazenada com maior eficiência nas baterias (Energia, 2015).

Os controladores de carga são utilizados principalmente em sistemas isolados da rede elétrica, ou seja, sistemas autônomos compostos por módulos fotovoltaicos ligados a um controlador, que por sua vez está ligado em baterias de alimentação e um inversor de frequência para a conversão da frequência da energia proveniente dos painéis fotovoltaicos, para que assim possa ser feita a alimentação dos equipamentos eletrônicos da residência (Energia, 2015).

A figura 2 ilustra o circuito de um controlador de carga PWM.

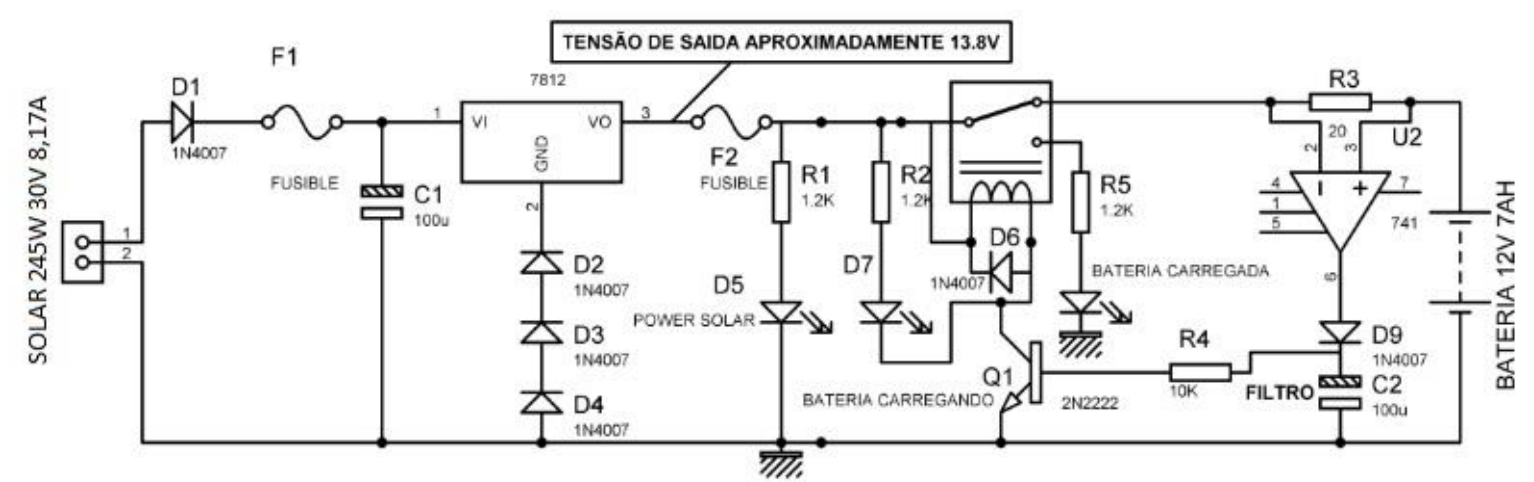

Figura 2 - Circuito Controlador de Carga. 


\subsection{Módulo de Armazenamento}

Para o Armazenamento da energia gerada utiliza-se uma bateria de $12 \mathrm{~V}$ e 7Ah, a qual armazena a energia gerada pela placa durante o dia, e conforme a demanda, irá suprir os equipamentos durante o período noturno onde a placa solar deixa de gerar energia.

O módulo de armazenamento só é possível no sistema off-grid, pelo fato de ser um sistema que trabalha de forma autônoma, ou seja, independente da rede elétrica necessitando assim de uma forma de armazenar a energia gerada para que não ocorra desperdícios de energia produzida aumentando a eficiência do sistema solar.

\subsection{Módulo de Conversão}

Uma das características que temos quanto à geração de energia solar é que, atualmente, todos os painéis solares produzidos geram energia elétrica em corrente contínua. Para alimentarmos aparelhos eletrônicos residenciais necessitamos de uma alimentação em corrente alternada para que os mesmos funcionem, com isso é necessário convertermos a energia de geração contínua em uma energia de alimentação alternada.

Para essa conversão foi utilizado um inversor de frequência contínua para alternada de 700 Watts de potência máxima, com alimentação de entrada de 12 Volts de corrente contínua e saída de 115 Volts de corrente alternada.

A figura 3 é uma ilustração de um circuito inversor 12V DC para 110V AC.

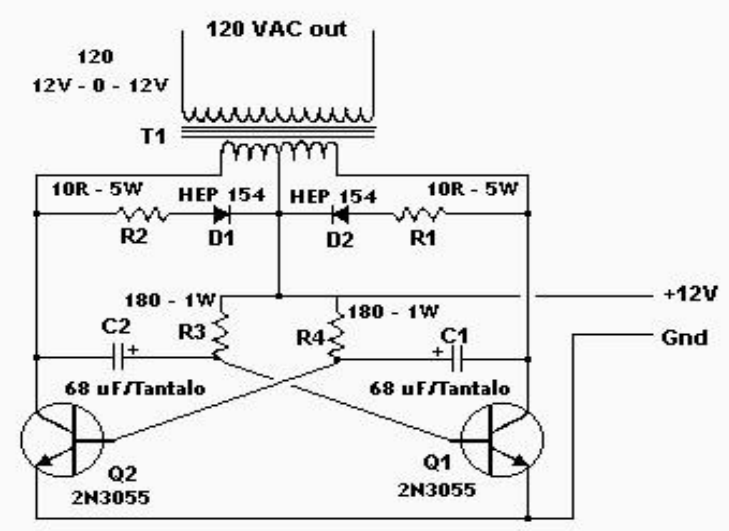

Figura 3 - Circuito de Inversor AC $110 \mathrm{v}$. 


\subsection{Módulo Digital}

Na parte digital encontra-se o circuito para o controle do posicionamento do painel fotovoltaico. Utiliza-se um Arduíno Uno e conjunto com resistores dependentes de luz para o melhor posicionamento do painel.

O esquemático do circuito está demonstrado na figura 4. Os sensores foram separados em dois lados, os sensores posicionados na lateral esquerda do painel que estão ligados a porta digital 2 do Arduíno e os sensores posicionados na lateral direita do painel que estão ligados a porta digital 3 do Arduíno, em série com os LDRs em cada lateral está um resistor para que possamos ter um referencial de resistência mínima igual nas duas laterais, afim de evitar interferências indesejadas na movimentação da placa.

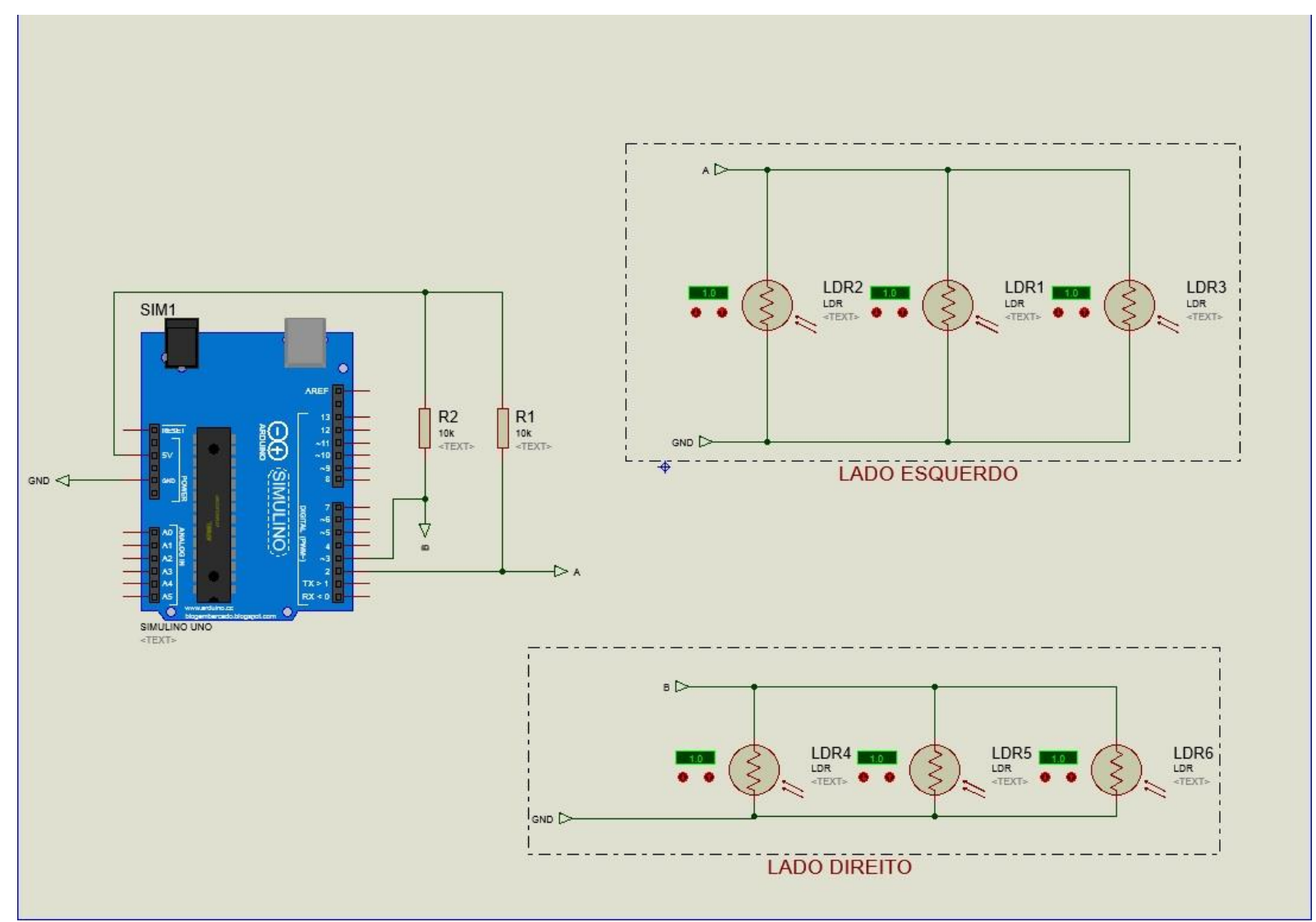

Figura 4 - Esquemático dos sensores de posicionamento da placa solar. 


\subsection{Módulo do Motor}

Para o controle da base onde se encontra o painel solar foi utilizado um motor de limpador de para-brisa de um carro, com acionamento através de um circuito de ponte $\mathrm{H}$ baseado no esquemático ilustrado na figura 4 .

O motor recebe os sinais enviados pelo Arduíno e posiciona a placa no eixo azimute conforme a variação estabelecida pelo microcontrolador.

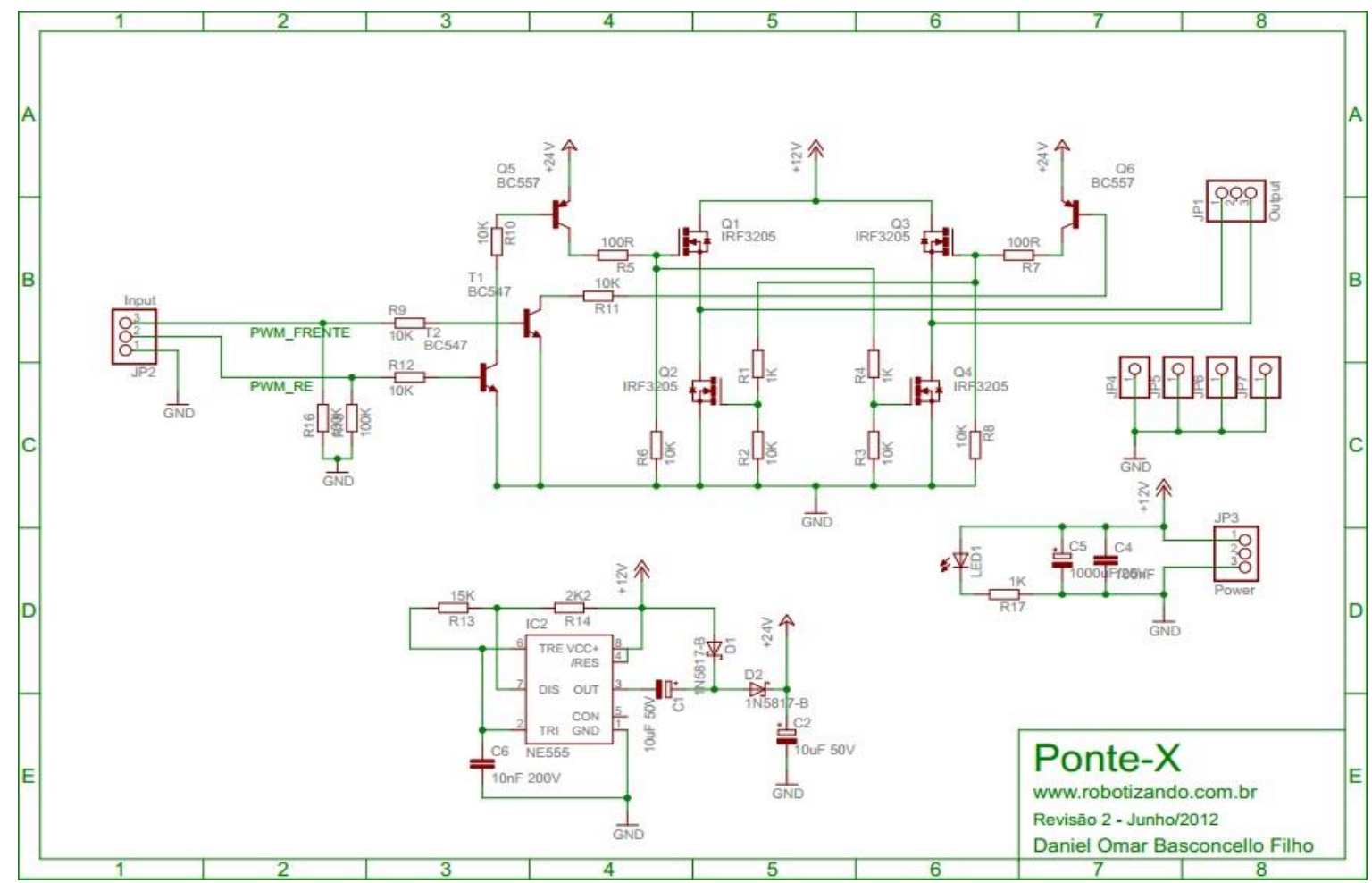

Figura 5 - Circuito de ponte $\mathrm{H}$ para controle do motor.

\section{Resultados}

Os resultados obtidos com o projeto foram satisfatórios no que tange a eficiência e controle do painel desejado inicialmente.

O painel fotovoltaico está ligado ao controlador de carga em uma entrada e a bateria que está ligada ao outro terminal do controlador de carga e liga-se em paralelo com o inversor de frequência conforme representado na figura 6. Na figura 7 podemos observar a leitura do multímetro da tensão de entrada do inversor que é de 13,5 V, após a corrente percorrer o circuito do inversor foi realizada outra medição, agora na saída, e obteve-se um valor de 114,1 $\mathrm{V}$ conforme a figura 8. 


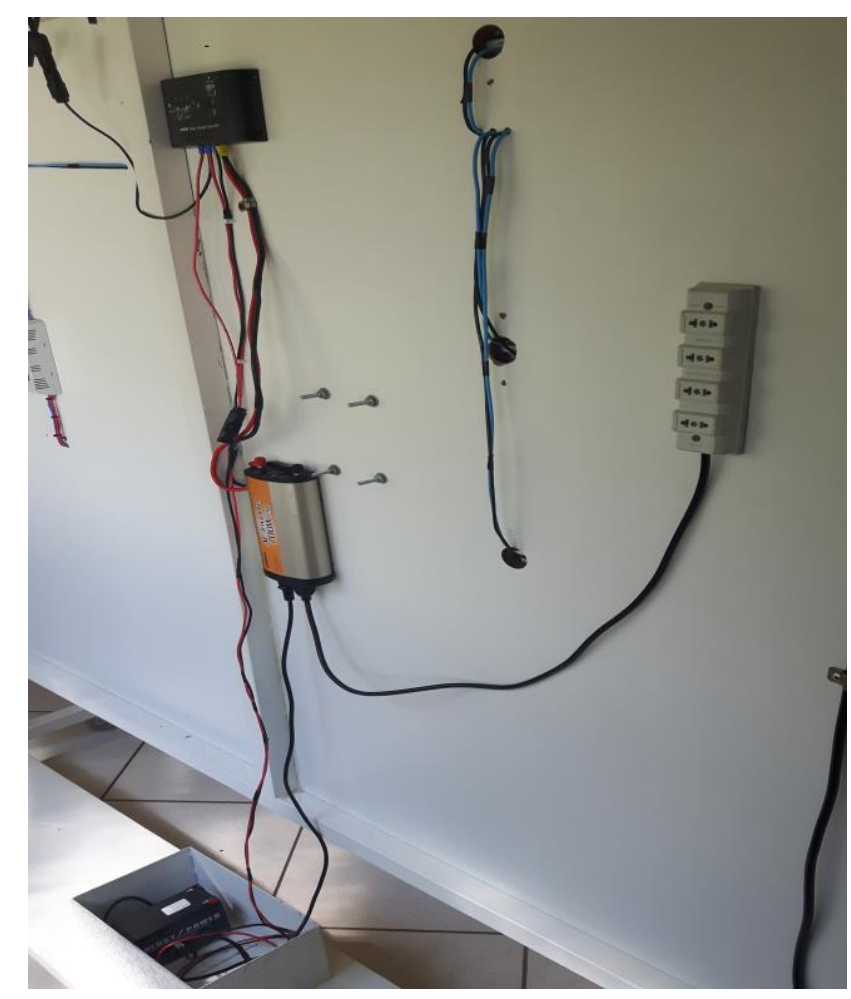

Figura 6 - Ligação do painel no circuito de controle, armazenamento e conversão.

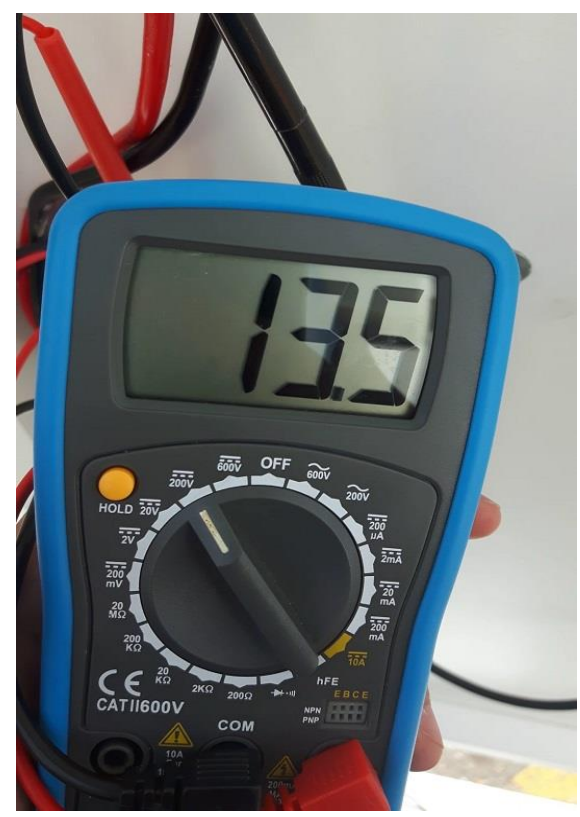

Figura 7 - Valor da tensão na entrada do inversor.

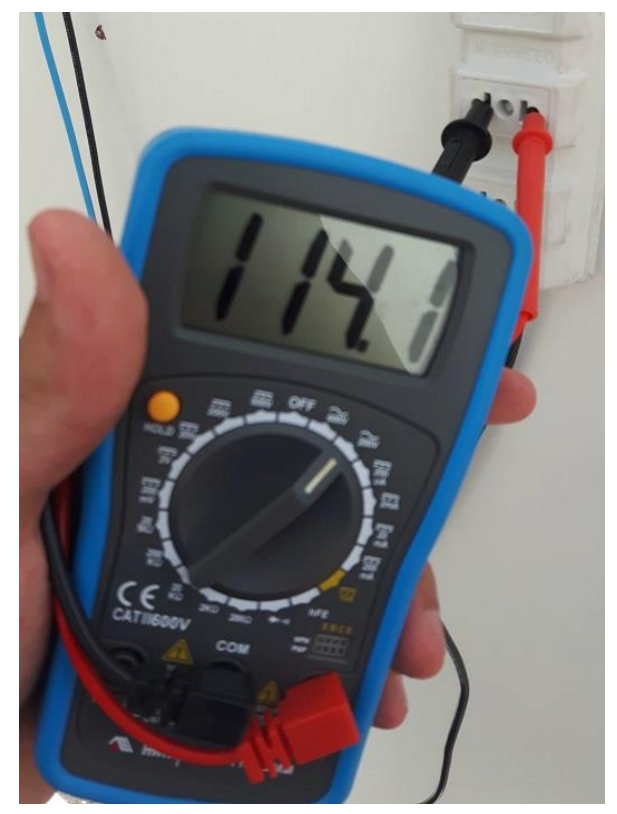

Figura 8 - Valor da tensão na saída do inversor.

O circuito inversor está alternando a corrente de entrada e ampliando a tensão na saída para cerca de $110 \mathrm{~V}$, essa tensão de saída é enviada para o quadro geral do painel residencial onde alimenta a entrada do disjuntor geral, que por sua vez após ser acionado alimenta as tomadas e as lâmpadas do painel residencial, a 
figura 9 representa a montagem final do projeto, com o painel solar já acoplado ao painel residencial.

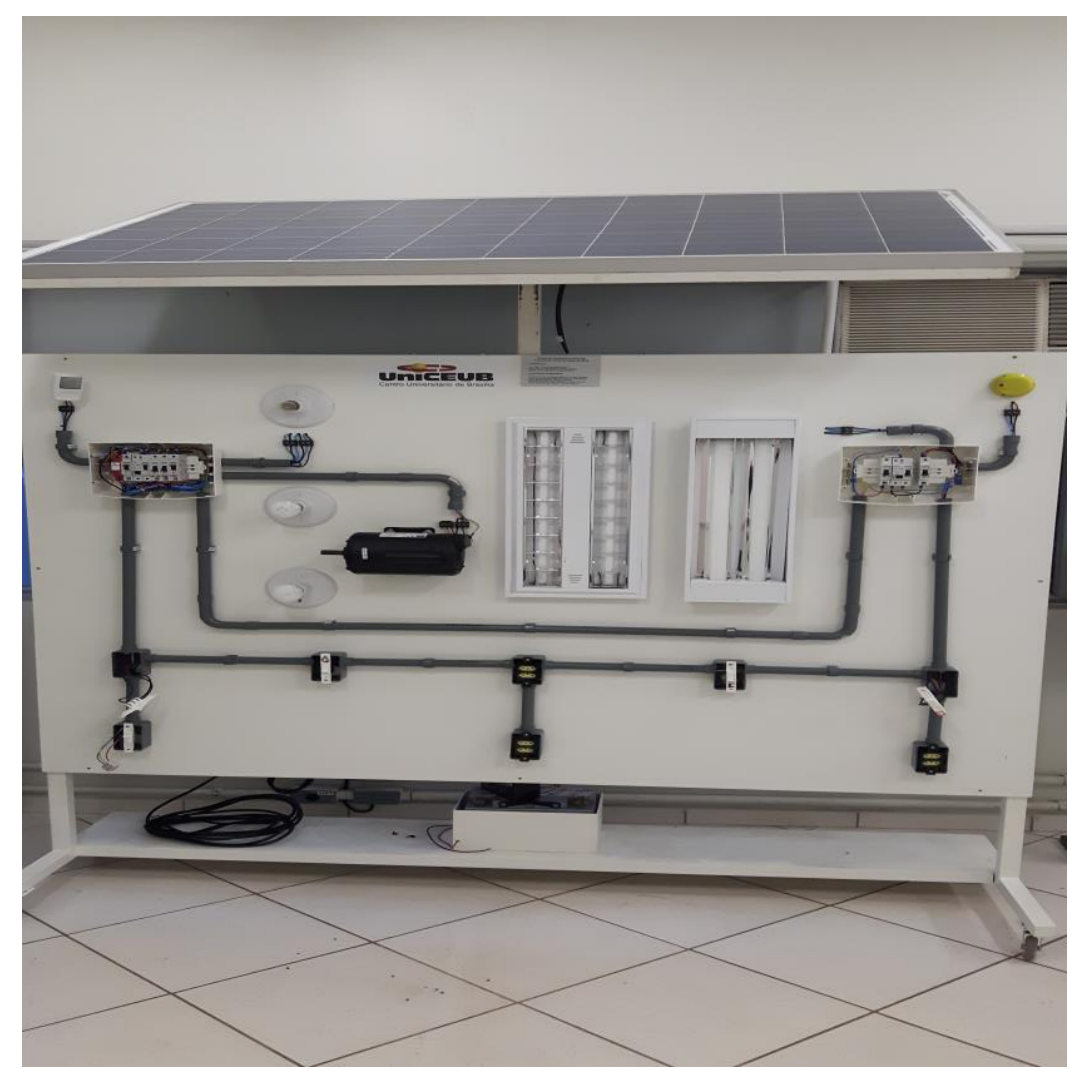

Figura 9 - Painel com a montagem final.

$\mathrm{Na}$ figura 10 temos o circuito de controle e acionamento do motor que irá posicionar o painel solar conforme a variação da intensidade luminosa incidente sobre o mesmo.

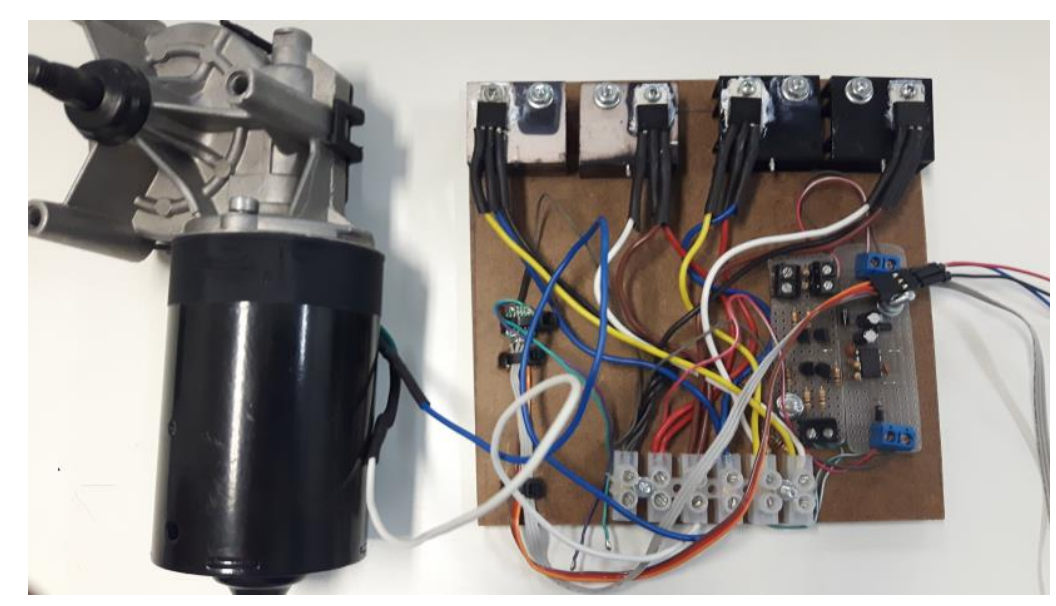

Figura 10 - Circuito final de controle e acionamento do motor. 


\section{Conclusão}

O projeto apresenta uma proposta de melhoramento na captação da energia solar e na geração de energia elétrica de forma a aumentar o ganho de uma célula fotovoltaica com a utilização de um microcontrolador, sendo possível deslocar o painel fotovoltaico, aproveitando mais a energia solar. Atualmente o trabalho encontra-se na fase de aprimoramento, testes finais do protótipo e desenvolvimento do software. Com o sistema proposto é possível produzir energia limpa e ter um melhor aproveitamento de uma fonte natural (Sol).

\section{Referências Bibliográficas}

ALVES, ALCEU FERREIRA; CAGNON, JOSE ANGELO. Desenvolvimento e Avaliação de Desempenho de um Sistema de Posicionamento Automático para Painéis Fotovoltaicos, 2010.

RIBEIRO, SANDRO CARNEIRO; PRADO, PEDRO PAULO LEITE DO; GONÇALVES, JOÃO BOSCO. Projeto e Desenvolvimento de um Rastreador Solar para Painéis Fotovoltaicos, 2012.

SOLAR TRACKING, Solar Tracking Systems Gain Ground, Disponível em: <http://www.renewableenergyworld.com/rea/news/article/2013/06/on-track-tosucceed-with-solar-tracking-systems>. Acesso em: Abril. 2016

GRID-TIE, Sistemas Conectados, Disponível em: http://www.neosolar.com.br/aprenda/saiba-mais/sistemas-conectados-grid-tie. Acesso em: Agosto. 2016

VERA, LUIS HORACIO. Programa Computacional para Dimensionamento e Simulação de Sistemas Fotovoltaicos Autônomos, 2004.

CEPEL - CRESESB, Manual de Engenharia para Sistemas Fotovoltaicos, 2004

PROTEUS - Labcenter Electronics,_Professional PCB Design and Simulation. Disponível em: < http://www.labcenter.com/>. Acesso em: Abril 2016.

ANEEL. Agência Nacional de Energia Elétrica. Disponível em: < http://www.aneel .org.br >. Acesso em: Julho. 2016.

ANEEL. (07 de 2016). Acesso em 20 de Agosto de 2016, disponível em Site da ANEEL: http://www2.aneel.gov.br/aplicacoes/atlas/pdf/03-Energia_Solar(3).pdf 
PROTEUS, Labcenter Eletronics. PROTEUS Versão Demo 8.1, Disponível em: http://www.labcenter.com/download/prodemo_download.cfm\#professional . Acesso em: Abril. 2016. 